\title{
REPORT OF THE COMMITTEE ON BREEDING COTTON.
}

DR. H. J. WeBBer, Ithaca, N. Y. Chairman, Prof. M. N. Harper, Clemson College, S. C., W. A. Órton, Washington, D. C., Prof. R. L. Bennetr, College Station, Tex., D. N.Shommaker, Washington, D.C.

Oxiscrs: To investigate and report on methods and technique of breeding cotton for various purposes, localities, and conditions; to encourage the production of improved purebred varieties of cotton for each agricultural region, and possibly for each soil in the cotton belt, and for each purpose.

(Report submitted by the Chairman.)

This committee has had no opportunity to meet together and has thus been compelled to continue its work by correspondence. The report the present season consists of special papers prepared by Dr. D. N. Shoemaker, Special Agent in Charge of Cotton Investigations, United States Department of Agriculture, and by Professor. D. A. Saunders, Special Agent of the United States Department of Agriculture. Copies of these papers are appended herewith as forming part of this report. The following extract from a letter report of Director J. N. Harper, of Clemson College, South Carolina, contains suggestions of value:

Judging from our experiments with cotton. I believe that it is highly necessary to study the environment of the cotton more closely and this before beginning with the breeding work. To my great surprise I have learned that the different varieties of cotton behave quite differently in their growth when grown on different types of soil and under varying climatic conditions. The Blue Ribbon cotton which does so well at our Experiment Station, goes to pieces when it is grown nearer the coast. The Sea Island blood seems to predominate. It takes on a big weedy growth producing very little lint and this not up to the standard. Some of the varieties that are the poorest at our Experiment Station are the very best on other types of soil, and this is such a big problem I hardly know how to go to work. I think that if our Station would expend considerable energy in determining the varieties of cotton best suited to the soil types found in the State it would furnish data on which we could get results. Our breeding and improving the Blue Ribbon cotton here at this place is of value to only a few farmers and our breeding work must necessarily be scattered over the State. The variety of cotton that you bred at Columbia is well suited to the sandy soils of a very large area, and it produced the very best fiber at our Experiment Station grounds this year. Whether or not this variety would suit the region nearer the coast is doubtful. In other words, there are zones of soil which require different types of cotton, bred along different lines. Just what these lines should be must be determined.

The importance of teaching cotton judging and breeding in the southern agricultural colleges has been forcibly called to the attention of the committee. Probably no crop, not excepting corn, is better suited to judging contests among students than is cotton. The corn-judging work, which has been extended so rapidly in the colleges of the central north and which has led to so many contests at various fairs and at the Chicago International, has had a profound effect in stimulating interest among students and bringing the colleges into closer contact with the farmer. Cotton judging can be made of the same importance and can be used to spread a knowledge 
of breeding methods. The combing of the staple while attached to the seed and the grading of a sample according to length of fiber, strength, fineness, spinning quality, uniformity on seed and on plant, percentage of lint to seed, etc., offer fine opportunity for the development of skill in judging. Combine with this, as is possible in the colleges of the South, the judging of the character of the plant, method of branching, size of boll, opening of boll, total yield, etci, and we have a fine subject for laboratory practice.

All of the first work mentioned in judging the quality of the lint can easily and profitably be carried out in classes in field crops in the northern colleges. Material of several varieties for such judging work could easily be obtained from any of the southern experiment stations. For the next report of the committee it is hoped to present score cards from various members of the committee for judging the different grades of cotton.

\section{REPORT ON HYBRIDS AND SELECTIONS OF COTTON.}

By Prof. D. A. Saunders, Special Agent, Department of Agriculture.

The plant-breeding work of the writer has been carried on under four or five distinct heads: (1) Straight selection; (2) making of hybrids between big-bolled and small-bolled cottons; (3) crossing of big-bolled cottons with big-bolled cottons; (4) crossing of longstaple upland with short-staple upland; (5) hybridizing of upland short and long staples by Sea. Island and Egyptian cottons.

\section{STRAIGHT SELECTION.}

In the straight selection of cottons for improvement in length of lint, earliness, etc., at least one type is distinct enough to be worthy of mention. It should properly be classed as a mutation. It is a selection of Boykin's big boll obtained three years ago. It has bolls a third larger than any of the commercial varieties of cotton, it averages 38 per cent lint, and gives a yield equal to that of any of the upland short-staple cottons. The lint on the Texas black land prairies under the most severe drought conditions of the past season, when even the upland short staples fell off at least one-eighth inch in length of fiber, ran from one and one-eighth inches to one and onefourth inches. It is early enough to escape the ravages of the weevil, and if it holds up to its present standard it will certainly be a most valuable cotton for the black-land prairie region of Texas. The lint was valued by a long-staple cotton buyer at $121 / 4$ cents on a basis of 11 cents for middling cotton.

\section{CROSSING BIG-BOLLED AND SMALL-BOLLED COTTONS.}

A number of crosses of this type were made and three of them have proven very satisfactory: (a) Triumph by King gave us a variety with bolls three-fourths as large as Triumph and much earlier in opening. The percentage of lint runs from 36 to 38 as against 38 to 41 per cent for Triumph. It is considerably earlier than. Triumph 
and holds up with it in yield. This is to be distributed the present season as Tring. (b) Triumph by Jones Prolific. Jones Prolific is an early-maturing round-boll cotton with a very high percentage of lint. Individual selections of it ran as high as 44 per cent. The weight of seed cotton in 10-boll samples is only 20 per cent less than that of Triumph, although the bolls appear to be much smaller. A uniform variety has been developed from this hybrid that runs from 38 to 40 per cent lint, is earlier in opening, and yielded the past season something over 10 per cent more seed cotton than the best selections of Triumph. It is being distributed this season as Crenshaw. (c) Triumph by Cook's Improved. This hybrid has given us a cotton somewhat similar to Crenshaw, but it has larger bolls and is especially adapted to river-bottom conditions where Triumph does not yield as well. It seems to be a very promising variety under these conditions.

In the majority of cases, however, hybrids made between the bigbolled and small-bolled varieties of cotton with no other object than earliness and size of boll are somewhat disappointing. Not enough gain was made in earliness to compensate for the loss in size of boll, which is the most important item from the standpoint of the Texas planter.

\section{CROSSING BIG-BOLLED WITH BIG-BOLLED COTTONS.}

A judicious combination of big-bolled varieties will, I believe, give the most satisfactory results for Texas upland conditions. Holmes, a variety of cotton exceptionally early in fruiting and opening, with large bolls, was found in South Texas, where it had been developed under extreme weevil conditions. On account of the dwarfed size of its stalk and its tendency to put on a definite amount of fruit and then stop, it did not make suitable yields in any of our variety tests. It yielded, moreover, only about $331-3$ per cent lint. $A$ cross between this cotton and Triumph, however, has given us one of the most promising things for weevil conditions. It is exceptionally early in opening and a very fine yielder and equal in all ways to the best upland varieties of cotton. With a couple years of careful selection, I believe it can be made the most satisfactory cotton from the standpoint of the commercial grower.

\section{LONG-STAPLE UPLAND CROSSED WITH SHORT-STAPLE UPLAND.}

Several crosses have been made between upland short-staple cottons and the best varieties of long-staple cottons in order to increase the yield, earliness and size as well as to obtain a long-staple cotton better adapted to Texas conditions. One of these crosses was made between Triumph and Sunflower three years ago and by careful selections a variety has been obtained with bolls fully as large as Triumph, a better yielder under river-bottom conditions, and having lint $13-8$ inches in length. The lint from this year's crop was valued by a long-staple buyer at $191 / 2$ cents on a basis of 11 cents for middling cotton. This is the same price as was placed 
on three-years' selection of Griffen's long staple, which did not hold up at all in yield on account of weevil conditions and dry weather. A cross between Triumph and Avard's long-staple in its second generation has given a variety with bolls larger than Triumph and exceptionally early and drought-resistant. It seems especially adapted to the stiffest land in river bottoms, where the average longstaple cottons do not hold up at all in yield. It is an exceptionally good yielder. The lint was graded as 1 3-16 inches and valued at $153 / 4$ cents on a middling basis of 11 cents. A hybrid between No. 451. (King by Bohemian) and Avard's long staple has given us in the second generation an exceptionally long-stapled cotton, but with a very low percentage of lint and a small boll. This, however, was very early and has an exceptionally long lint, so that it seemed best to grow it for a few years for careful selection and also to use it as a basis for further hybridizing. It was graded by a practical cotton buyer as full $11 / 2$ to $19-16$ inches long and very strong, and was valued at 26 cents per pound on a basis of 11 cents for middling. It yielded more seed cotton this year than anything on the plantation. Notice that it was multiple.

\section{MULTIPLE HYBRIDS.}

An interesting series of hybrids is under way which promises something of economic importance. A hybrid made three years ago between King and Egyptian (551 A) has given us an early-maturing cotton with bolls as large as King and very abundant brownish lint, but only about one inch in length. Selected plants of Griffen's long-staple with the longest lint and largest bolls were combined with this, using Griffen both as the male and female parent. The first generation grown last season at Shreveport gave a most remarkably early series, the bolls all being open at the first picking of the rest of the crop. The lint was of a soft creamy yellow tint, $15-16$ inches in length, and valued at 171/2 cents on a middling basis of 11 cents. The bolls are as large as Griffen and the plant very hardy and productive. Mr. Foster, upon whose plantation the work was carried on, stated that he noticed all through the season how much healthier and earlier this row of plants seemed to be. Two reciprocal rows of this combination were grown side by side and gave the following results for the first generation: I. Griffen $X$ (King by Egyptian) had long lint (1 5-16 to $11 / 2$ inches) of lighter color with larger seed, the top mostly white bolls, and much foliage very similar to Griffen. II. (King by Egyptian) X Griffen had shorter lint ( $1 \frac{1}{8}$ to $11 / 4$ inches) of a darker color, tuft dark or absent, seed very small, bolls small and roundish like the female parent, foliage intermediate. This tends to prove what $I$ have contended for the past two years: that is that in cotton the female parent was much stronger in its transmitting power. Occasionally, however, I get some results that do not seem to correspond to this rule. Another hybrid between Griffen and Sea Island by Storm Proof gave a good-yielding cotton in the first generation with large bolls and exceptionally fine lint 
which graded 1 5-8 inches and was very strong; and it was valued at 28 cents on a basis of 11 cents. for middling. It was earlier than the average selections of Griffen, Allen, and Avard's long-staples. and gave better yields than any of these selections the past season.

\title{
FUTURE WORK.
}

From my experience, not only the greatest variation but the greatest tendency to vary in the right direction (upward direction) is obtained, at least in cotton breeding, from multiple hybrids or a hybrid between a fixed variety and an unstable hybrid of the first or second generation. A large number of this type of crosses and hybrids were made two years ago and almost without exception each one of these has given something more valuable than either of the parents. I intend to carry this one step further at least by reducing the Barbadense blood to one-eighth and, second, by crossing unfixed hybrids with unfixed or multiple hybrids or the third degree, and, third, by crossing unfixed hybrids with fixed varieties.

\section{REPORT OF COMMITTEE ON BREEDING FIBER CROPS.}

\author{
Prof. J. H. Shepperd, Fargo, N. Dak., Prof. H. L. Bollex, Fargo, N. Dak., \\ Chairman, \\ Prof. Fritz Knorr, Ft. Collins, Colo. \\ L. H. DEweY, Washington, D. C.,
}

OBJEcTs: To investigate and report on methods of breeding fiber crops other than cotton, such as hemp, flax (for fiber and also for seed), and ramie; and to encourage the production of improved purebred varieties for each agricultural region needing them and for each use.

(Report submitted by Chairman.)

Your Chairman of the Committee on Breeding Fiber Plants desires to report that it was decided to leave out the most important crop in the list, viz., cotton, this season and suggests that the committee give large attention to that crop another year. The work of cotton breeding has received much scientific investigation which has been published and widely distributed so that less need of information relative to it exists than for the breeding and management of the other fiber crops. Your committee has made a division of labor in preparing a report to present to you.

Dr. Lyster H. Dewey of the United States Department of Agriculture presents the general survey of the situation, giving the needs, present conditions, demands, and limitations--territorial and otherwise-for each of the fiber crops.

Professor Fritz Knorr of the Colorado Experiment Station has discussed hemp culture and breeding based upon his experience as a grower in the hemp-producing region of Kentucky, his experience and observation while experimenting with it at the Minnesota Experiment Station, and his results together with illustrations showing what he has accomplished with this fiber plant in Colorado. 